\title{
FAKTOR-FAKTOR YANG BERHUBUNGAN DENGAN KONTAK PANAS SECARA LANGSUNG TERHADAP GEJALA DERMATITIS PADA PEKERJA DI PT. ELANGPERDANA TYRE INDUSTRY CITEUREUP TAHUN 2019
}

\author{
Khairunnisa Anas ${ }^{1)}$, Anissatul Fathimah ${ }^{2)}$, dan Rubi Ginanjar ${ }^{3)}$ \\ ${ }^{1)}$ Keselamatan dan Kesehatan Kerja (K3), Program Studi Kesehatan Masyarakat Fakultas Ilmu Kesehatan, Universitas \\ Ibn Khaldun Bogor, Email : khairunnisa.anas97@gmail.com \\ ${ }^{2)}$ Keselamatan dan Kesehatan Kerja (K3), Program Studi Kesehatan Masyarakat Fakultas Ilmu Kesehatan, Universitas \\ Ibn Khaldun Bogor, Email : anissatulfathimah@yahoo.com \\ ${ }^{3)}$ Keselamatan dan Kesehatan Kerja (K3), Program Studi Kesehatan Masyarakat Fakultas Ilmu Kesehatan, Universitas \\ Ibn Khaldun Bogor, Email : rubi.ginanjar@gmail.com
}

\begin{abstract}
Abstrak
Gejala dermatitis dapat terjadi di lingkungan PT.Elangperdana Tyre Industry pada bagian curing, mixing, calendar, extruding dan finishing karena pada beberapa proses kerja yang memungkinkan para pekerja kontak dengan material panas. Tujuan dari penelitian ini adalah untuk mengetahui adanya hubungan antara kontak panas langsung dengan gejala dermatitis pada pekerja di PT.Elangperdana Tyre Industry Citeureup tahun 2019. Desain penelitian ini merupakan jenis penelitian kuantitatif dengan desain penelitian menggunakan pendekatan cross-sectional. Pada penelitian ini variabel dependen dan variabel independen diamati pada waktu yang bersamaan. Populasi yang digunakan dalam penelitian ini yaitu sebanyak 2212 pekerja bagian produksi di PT.Elangperdana Tyre Industry. Sampel yang diambil dengan teknik sample size dengan responden sebanyak 78 responden.Pengambillan data menggunakan kuesioner serta melakukan pengukuran suhu material panas menggunakan alat fluke thermometer. Analisis data dalam penelitian ini menggunakan uji statistik chi square. Hasil analisis menunjukkan tidak ada hubungan antara suhu material dengan gejala dermatitis, umur, masa kerja, lama kontak, dan penggunaan alat pelindung diri. Kesimpulan dari penelitian ini adalah area kerja yang berisiko terkena gejala dermatitis dikarenakan pekerja seringkali kontak dengan material bersuhu tinggi. Namun pada beberapa divisi sudah mengantisipasi dengan menggunakan alat pelindung diri berlapis akan tetapi menurut peneliti hal ini tidak efektif sebab menambah biaya pengadaan APD.
\end{abstract}

\section{Kata Kunci: Kontak Panas, Industri, Gejala Dermatitis}

\section{Pendahuluan}

Penyakit akibat kerja adalah penyakit yang disebabkan oleh pekerjaan, alat kerja, bahan, proses maupun lingkungan kerja. Dengan demikian, penyakit akibat kerja merupakan penyakit yang artifisual atau man made disease. Sejalan dengan hal tersebut dijelaskan bahwa Penyakit Akibat Kerja
(PAK) ialah gangguan kesehatan baik jasmani maupun rohani yang ditimbulkan ataupun diperparah karena aktivitas kerja atau kondisi yang berhubungan dengan pekerjaan (Hebbie Ilma Adzim, 2013). Penelitian WHO pada pekerja tentang penyakit akibat kerja di 5 (lima) benua tahun 1999, memperlihatkan 
bahwa penyakit gangguan otot rangka (Musculosceletal Disease) pada urutan pertama $48 \%$, kemudian gangguan jiwa $10-$ $30 \%$, penyakit paru obstruksi kronis $11 \%$, penyakit kulit (Dermatosis) akibat kerja 10\%, gangguan pendengaran 9\%, keracunan pestisida 3\%, cedera dan lain-lain. (Depkes RI,2008).

Di Indonesia, PKAK belum mendapat perhatian khusus dari pemerintah atau pemimpin perusahaan walaupun jenis dan tingkat prevalensinya cukup tinggi. (Puspita, 2012). Sumamur (1986) memperkirakan bahwa 50-60\% dari seluruh penyakit akibat kerja adalah penyakit kulit akibat kerja. Dari data sekunder ini terlihat bahwa PKAK memang mempunyai prevalensi yang cukup tinggi, walaupun jenis tidak sama pada semua perusahaan. Variasi penyakit kulit di setiap perusahaan sangat berbeda, karena setiap perusahaan/industri proses produksi dan lingkungan dalam perusahaan serta bahan yang dipergunakan di setiap perusahaan berbeda-beda. Berdasarkan data yang didapatkan di U.S. Bureau of Labour Statistic menunjukkan bahwa 249.000 kasus penyakit okupasional nonfatal pada tahun 2004 untuk kedua jenis kelamin 15,6\% (38.900 kasus) adalah penyakit kulit yang merupakan penyebab kedua terbesar untuk semua penyakit okupasional. Juga berdasarkan survei tahunan dari institusi yang sama, bahwa incident rate untuk penyakit okupasional pada populasi pekerja di Amerika, 90-95\% dari penyakit okupasional adalah dermatitis kontak, dan $80 \%$ dari penyakit didalamnya adalah dermatitis kontak iritan. Pada sebagian besar kasus, kedua jenis ini akan muncul sebagai lesi eksema pada bagian tubuh yang terpapar, terutama tangan. (Wolff. K,2008).

Di Indonesia prevalensi dermatitis kontak sangat bervariasi. Menurut Perdoski (2009) sekitar 90\% penyakit kulit akibat kerja merupakan dermatitis kontak, baik iritan maupun alergik. Penyakit kulit akibat kerja yang merupakan dermatitis kontak sebesar 92,5\%, sekitar 5,4\% karena infeksi kulit dan $2,1 \%$ penyakit kulit karena sebablain. Pada studi epidemiologi, Indonesia memperlihatkan bahwa 97\% dari 389 kasus adalah dermatitis kontak, dimana $66,3 \%$ diantaranya adalah dermatitis kontak iritan dan $33,7 \%$ adalah dermatitis kontak alergi.(Hudyono, 2002). Menurut Erliana (2008) beberapa penelitian menunjukkan bahwa penyakit dermatitis kontak merupakan penyakit yang lazim terjadi pada pekerja yang berhubungan dengan bahan kimia dan panas, serta faktor mekanik sebagai gesekan, tekanan dan trauma. Prevalensi DKAK di Indonesia menurut Djuanda et al. (2010) sulit didapat karena pada umumnya penderita DKAK dengan keluhan ringan tidak datang berobat atau bahkan tidak mengeluh. Angka kejadian DKAK menurut Lestari \& Utomo (2007) adalah 20-50 kali lebih tinggi dari angka kejadian yang dilaporkan. Walaupun penyakit ini jarang membahayakan jiwa, menurut Brown (2004) dapat mempengaruhi kualitas hidup penderita.

Pada beberapa tingkat tekanan panas, mekanisme kompensasi pekerja tidak lagi mampu mempertahankan suhu tubuh pada tingkat yang diperlukan untuk fungsi tubuh normal. Akibatnya, risiko penyakit, gangguan, dan bahaya terkait panas lainnya meningkat. Tingkat stres panas di mana ketegangan panas yang berlebihan akan terjadi tergantung pada kemampuan toleransi panas pekerja. Namun, meskipun ada berbagai toleransi panas antara pekerja, masing-masing pekerja memiliki batas atas untuk tekanan panas, di luar yang mengakibatkan ketegangan panas dapat menyebabkan pekerja menjadi korban panas.

Pada sebagian besar pekerja, paparan berulang yang tepat terhadap tekanan panas 
tinggi menyebabkan serangkaian adaptasi fisiologis yang disebut aklimatisasi, di mana tubuh menjadi lebih efisien dalam mengatasi tekanan panas (OSHA, 2012). Pada tahun 1979 di Amerika, total dari insiden heat strain dengan kehilangan hari kerja paling kecil satu hari diestimasikan sebesar 1.432 kasus. Menurut data kasus dikarenakan sakit akibat panas per 100.000 pekerja adalah pada area perkebunan (9,16 kasus/ 100.000 pekerja), konstruksi (6,36 kasus/ 100.000 pekerja), dan tambang (5,01 kasus/100.000 pekerja) (NIOSH, 1986).

Dari hasil observasi peneliti menemukan risiko terjadinya dermatitis pada pekerja bagian Curing di PT.Elangperdana

\section{Metode}

Penelitian ini dilakukan dengan menggunakan pendekatan kuantitatif dengan desain Cross Sectional. Populasi dalam penelitian ini adalah pekerja bagian produksi di PT.Elangperdana Tyre Industry sebanyak 2212 orang. Sampel dalam penelitian ini berfokus pada divisi curing, mixing, calendar, extruding dan finishing yaitu sebanyak 78 responden. Untuk menentukan besar sampel dalam penelitian ini menggunakan rumus perhitungan pada aplikasi sample size seperti berikut

\section{Diketahui :}

$$
\begin{array}{ll}
\mathrm{P}_{1} & : 81.8 \%=0.82 \text { (berdasarkan penelitian } \\
& \text { terdahulu) } \\
\mathrm{P}_{2} & : 43.5 \%=0.44 \text { (berdasarkan penelitian } \\
& \text { terdahulu) } \\
\mathrm{P} & :-\quad 0.63 \\
\mathrm{Z1} 1-\alpha & : \text { Derajat kemaknaan } \alpha \text { pada uji 1sisi } \alpha \\
\mathrm{Z} 1-\beta & : \text { Kekuatan uji } 90 \%
\end{array}
$$

Tyre Industry, Prevalensi kemungkinan terjadinya dermatitis cukup tinggi disebabkan pekerja yang mengangkut ban panas bahkan dalam keadaan ban masih mengeluarkan asap (baru selesai proses pematangan) di mesin press curing ke rollie hanya menggunakan tangan dan APD seadanya yaitu sarung tangan kain untuk meredam sedikit rasa panas dari ban tersebut.

Berdasarkan hal tersebut dan latar belakang yang telah dijelaskan peneliti tertarik untuk melakukan penelitian mengenai hubungan antara kontak panas langsung dengan gejala dermatitis di bagian curing PT.Elangperdana Tyre Industry, Citeureup tahun 2019.

Data yang digunakan dalam penelitian ini hanya data primer dikarenakan peneliti tidak mendapatkan data sekunder seperti hasil medical check up responden 5 tahun terakhir. Data primer diperoleh langsung dari hasil wawancara peneliti dengan responden menggunakan kuesioner yang berisi pertanyaan berhubungan dengan gejala dermatitis yang kemungkinan diderita pekerja bagian produksi PT.Elangperdana Tyre Industry. Instrumen yang digunakan dalam penelitian ini adalah dengan menggunakan kuesioner dan lembar observasi yang didalamnya berisi variabel-variabel yang telah ditentukan sebelumnya serta melakukan pengukuran suhu ban panas menggunakan alat fluke thermometer. Penelitian akan dilakukan di PT. Elangperdana Tyre Industry terutama di salah satu area produksi yaitu di bagian curing, mixing, calendar, extruding, dan finishing pada bulan Juni-Agustus 2019. 


\section{Hasil}

Hasil analisis univariat pada gejala dermatitis diperoleh dari diagnosa dokter, diketahui bahwa dari 78 responden terdapat 47 responden $(60.3 \%)$ tidak mengalami gejala dermatitis sedangkan 31 responden $(39.7 \%)$ mengalami gejala dermatitis kontak. Dari data yang diperoleh banyaknya responden yang kontak dengan material panas dengan suhu rata-rata $35-40^{\circ} \mathrm{C}$ sebanyak 22 responden (28.2\%) sedangkan pekerja yang kontak langsung dengan material suhu diatas $40^{\circ} \mathrm{C}$ yaitu sebanyak 56 responden (71.8\%). Pada variabel umur diketahui bahwa umur responden yang kurang dari 31 tahun sebanyak 40 responden (51.3\%). Sedangkan umur responden dengan ketentuan lebih dari atau sama dengan 31 tahun sebanyak 38 responden $(48.7 \%)$. Frekuensi paling banyak pada variabel masa kerja terdapat 66 responden $(84.6 \%)$ responden yang telah bekerja selama $>=5$ tahun dan frekuensi paling sedikit terdapat pada variabel masa kerja yaitu pekerja yang bekerja kurang dari 5 tahun sebanyak 12 responden (15.4\%).

Distribusi frekuensi berdasarkan lama kontak diketahui responden yang lama kontak dengan material pada kategori $<5$ jam dalam sehari sebesar 58 responden $(74.4 \%)$, yaitu 2.5 kali lebih banyak daripada kategori lama kontak >=5 jam yang hanya sebesar 20 reponden atau setara dengan $25.6 \%$. Hasil distribusi frekuensi penggunaan alat pelindung diri dapat dilihat dari banyaknya responden yang konsisten menggunakan pelindung sarung tangan saat bersentuhan dengan material panas adalah 59 responden (75.6\%). Kemudian diketahui pula ada 19 responden (24.4\%) yang beberapa kali terlihat tidak menggunakan sarung tangan saat bekerja maka masuk ke dalam kategori tidak konsisten dalam penggunaan APD.

Tabel 1. Distribusi hubungan antara Suhu Material terhadap Gejala Dermatitis pada pekerja di PT. ElangPerdana Tyre Industry tahun 2019

\begin{tabular}{|c|c|c|c|c|c|c|c|c|}
\hline \multirow{3}{*}{$\begin{array}{c}\text { Suhu } \\
\text { Material }\end{array}$} & \multicolumn{6}{|c|}{ Gejala Dermatitis } & \multirow{3}{*}{$\begin{array}{c}\text { OR } \\
95 \% \text { CI }\end{array}$} & \multirow{3}{*}{ P-value } \\
\hline & \multicolumn{2}{|c|}{ Dermatitis } & \multicolumn{2}{|c|}{$\begin{array}{c}\text { Tidak } \\
\text { Dermatitis }\end{array}$} & \multicolumn{2}{|c|}{ Total } & & \\
\hline & $\mathrm{N}$ & $\%$ & $\mathrm{~N}$ & $\%$ & $\mathrm{~N}$ & $\%$ & & \\
\hline $36-40^{\circ} \mathrm{C}$ & 11 & 50 & 11 & 50 & 22 & 100 & \multirow{2}{*}{$\begin{array}{c}0.556 \\
0.205-1.508\end{array}$} & \multirow[t]{2}{*}{0.246} \\
\hline$>40^{\circ} \mathrm{C}$ & 20 & 35.7 & 36 & 64.2 & 56 & 100 & & \\
\hline Jumlah & 31 & 39.7 & 47 & 60.3 & 78 & 100 & & \\
\hline $\begin{array}{l}\text { Berdasa } \\
\text { lengan me } \\
\text { lidapatkan ni }\end{array}$ & $\mathrm{n}$ & $\begin{array}{ll}\text { sil } & \text { an } \\
\mathrm{n} & \mathrm{uj} \\
\text { ce } & \text { sebe }\end{array}$ & $\begin{array}{l}\text { is } \\
\text { Chi } \\
0,2\end{array}$ & $\begin{array}{l}\text { istik } \\
\text { uare } \\
\text { Hal }\end{array}$ & $\begin{array}{l}\text { ge } \\
\text { PT }\end{array}$ & $\begin{array}{l}\text { berm } \\
\text { a } \\
\text { langp }\end{array}$ & $\begin{array}{l}\text { a antara suhu } \\
\text { rmatitis }\end{array}$ & $\begin{array}{r}\text { terial denga } \\
\text { peker } \\
\text { ahun } 2019 \text {. }\end{array}$ \\
\hline
\end{tabular}

ini menunjukan bahwa tidak ada hubungan 
Tabel 2. Distribusi hubungan antara Umur terhadap Gejala Dermatitis pada pekerja di PT. ElangPerdana Tyre Industry tahun 2019

\begin{tabular}{|c|c|c|c|c|c|c|c|c|}
\hline \multirow{3}{*}{ Umur } & \multicolumn{6}{|c|}{ Gejala Dermatitis } & \multirow{3}{*}{$\begin{array}{c}\text { OR } \\
95 \% \text { CI }\end{array}$} & \multirow{3}{*}{ P-value } \\
\hline & \multicolumn{2}{|c|}{ Dermatitis } & \multicolumn{2}{|c|}{$\begin{array}{c}\text { Tidak } \\
\text { Dermatitis }\end{array}$} & \multicolumn{2}{|c|}{ Total } & & \\
\hline & $\mathrm{N}$ & $\%$ & $\mathrm{~N}$ & $\%$ & $\mathrm{~N}$ & $\%$ & & \\
\hline$<31$ tahun & 15 & 37.5 & 25 & 62.5 & 40 & 100 & $\begin{array}{c}1.212 \\
0.80-3005\end{array}$ & 0.678 \\
\hline$>=31$ tahun & 16 & 42.1 & 22 & 57.9 & 38 & 100 & & \\
\hline Jumlah & 31 & 39.7 & 47 & 60.3 & 78 & 100 & & \\
\hline $\begin{array}{l}\text { Berdasark } \\
\text { dengan meng } \\
\text { didapatkan nilai }\end{array}$ & ha & $\begin{array}{l}\text { anal } \\
\text { uji } \\
\text { sebes }\end{array}$ & $\begin{array}{l}\text { S s } \\
\text { Chi- } \\
0.67\end{array}$ & $\begin{array}{l}\text { stik } \\
\text { are } \\
\text { Hal }\end{array}$ & & berm & $\begin{array}{l}\text { antara umur } \\
\text { pekerja } \mathrm{P}^{\prime} \\
\text { un } 2019 \text {. }\end{array}$ & $\begin{array}{l}\text { gan gejal } \\
\text { angperdan }\end{array}$ \\
\hline
\end{tabular}

ini menunjukan bahwa tidak ada hubungan

Tabel 3. Distribusi hubungan antara masa kerja terhadap gejala dermatitis pada pekerja di PT. ElangPerdana Tyre Industry tahun 2019

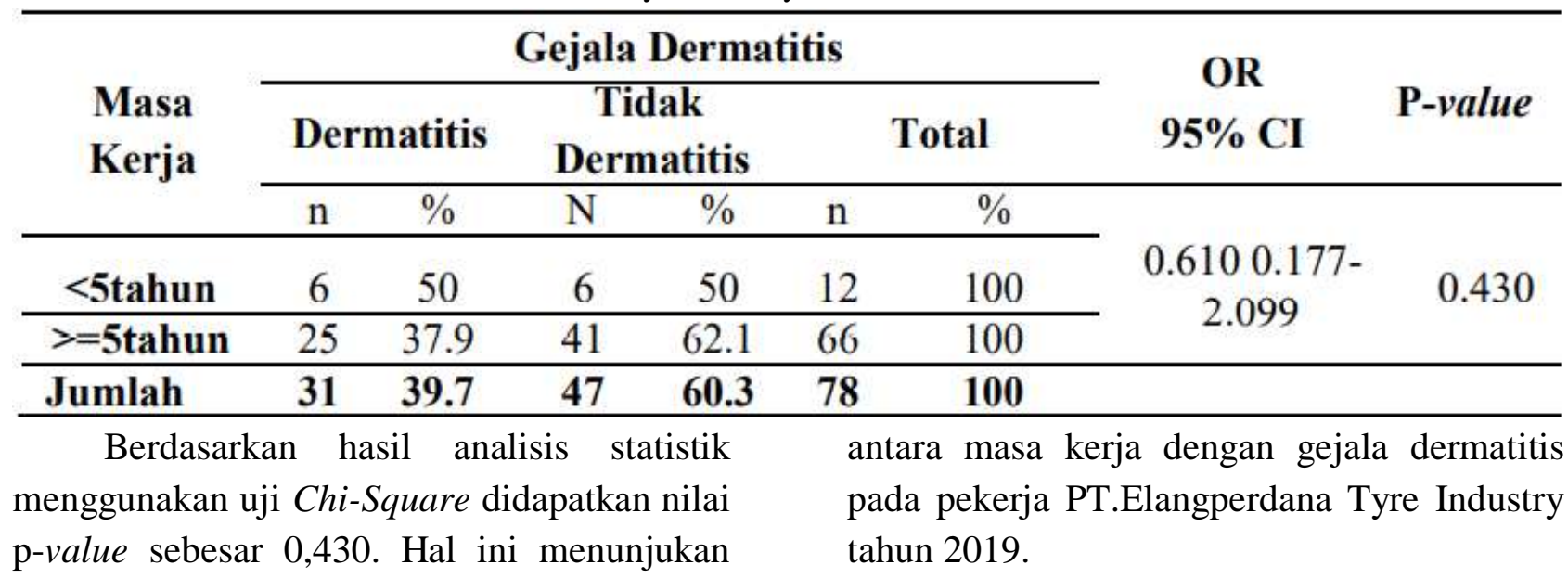

bahwa tidak ada hubungan yang bermakna

Tabel 4. Distribusi hubungan antara lama kontak terhadap gejala dermatitis pada pekerja di PT. ElangPerdana Tyre Industry tahun 2019

\begin{tabular}{|c|c|c|c|c|c|c|c|c|}
\hline \multirow{3}{*}{$\begin{array}{c}\text { Lama } \\
\text { Kontak }\end{array}$} & \multicolumn{6}{|c|}{ Gejala Dermatitis } & \multirow{2}{*}{$\begin{array}{c}\text { OR } \\
95 \% \mathrm{CI}\end{array}$} & \multirow[b]{2}{*}{ P-value } \\
\hline & \multicolumn{2}{|c|}{ Dermatitis } & \multicolumn{2}{|c|}{$\begin{array}{c}\text { Tidak } \\
\text { Dermatitis }\end{array}$} & \multicolumn{2}{|c|}{ Total } & & \\
\hline & $\mathrm{n}$ & $\%$ & $\mathrm{~N}$ & $\%$ & $\mathrm{n}$ & $\%$ & \multirow{3}{*}{$\begin{array}{c}1.014 \\
0.359-2.864\end{array}$} & \multirow{3}{*}{0.978} \\
\hline$<5$ jam & 23 & 39.7 & 35 & 60.3 & 58 & 100 & & \\
\hline$>=5$ jam & 8 & 40 & 12 & 60 & 20 & 100 & & \\
\hline Jumlah & 31 & 39.7 & 47 & 60.3 & 78 & 100 & & \\
\hline \multicolumn{5}{|c|}{$\begin{array}{l}\text { Berdasarkan hasil analisis statistik } \\
\text { menggunakan uji Chi-Square didapatkan nilai } \\
\text { p-value sebesar } 0,978 \text {. Hal ini menunjukan } \\
\text { bahwa tidak ada hubungan yang bermakna } \\
\text { antara lama kontak dengan gejala dermatitis }\end{array}$} & \multicolumn{4}{|c|}{$\begin{array}{l}\text { pada pekerja PT,Elangperdana Tyre Industr } \\
\text { tahun 2019. Selanjutnya hasil analisi } \\
\text { didapatkan "Odd Ratio (OR)" sebesar } 1,01 \\
\text { artinya responden yang terpapar materia } \\
\text { dengan akumulasi lama kontak selama } 5 \text { jan }\end{array}$} \\
\hline
\end{tabular}


atau lebih mempunyai peluang mengalami gejala dermatitis sebesar 1.014 kali lebih besar dibandingkan dengan responden yang terpapar material dengan akumulasi waktu lama kontak kurang dari 5 jam.

Tabel 5. Distribusi hubungan antara Penggunaan Alat Pelindung Diri terhadap gejala dermatitis pada pekerja di PT. ElangPerdana Tyre Industry tahun 2019

\begin{tabular}{|c|c|c|c|c|c|c|c|c|}
\hline \multirow{3}{*}{$\begin{array}{c}\text { Penggunaan } \\
\text { Alat } \\
\text { Pelindung } \\
\text { Diri }\end{array}$} & \multicolumn{6}{|c|}{ Gejala Dermatitis } & \multirow{3}{*}{$\begin{array}{c}\text { OR } \\
95 \% \text { CI }\end{array}$} & \multirow{3}{*}{$\begin{array}{c}\mathrm{P}- \\
\text { value }\end{array}$} \\
\hline & \multicolumn{2}{|c|}{ Dermatitis } & \multicolumn{2}{|c|}{$\begin{array}{c}\text { Tidak } \\
\text { Dermatitis }\end{array}$} & \multicolumn{2}{|c|}{ Total } & & \\
\hline & $\mathrm{n}$ & $\%$ & $\mathrm{n}$ & $\%$ & $\mathrm{n}$ & $\%$ & & \\
\hline Konsisten & 25 & 42.37 & 34 & 57.63 & 59 & 100 & \multirow{2}{*}{$\begin{array}{c}0.628 \\
0.210-1.879\end{array}$} & \multirow{2}{*}{0.403} \\
\hline $\begin{array}{c}\text { Tidak } \\
\text { Konsisten } \\
\end{array}$ & 6 & 31.58 & 13 & 68.42 & 19 & 100 & & \\
\hline Jumlah & 31 & 39.74 & 47 & 60.26 & 78 & \multicolumn{2}{|c|}{100} & \\
\hline \multicolumn{5}{|c|}{$\begin{array}{l}\text { Berdasarkan hasil analisis statistik } \\
\text { menggunakan uji Chi-Square didapatkan nilai } \\
\text { p-value sebesar } 0,403 \text {. Hal ini menunjukan } \\
\text { bahwa tidak ada hubungan yang bermakna } \\
\text { antara penggunaan alat pelindung diri dengan }\end{array}$} & \multicolumn{4}{|c|}{$\begin{array}{l}\text { "Odd Ratio (OR)" sebesar } 0,628 \text { responde } \\
\text { yang tidak konsisten menggunakan al } \\
\text { pelindung diri mempunyai peluan } \\
\text { mengalami gejala dermatitis sebesar } 0.62 \\
\text { kali lebih besar dibandingkan denga } \\
\text { responden yang konsisten menggunakan al } \\
\text { pelindung diri. }\end{array}$} \\
\hline
\end{tabular}

\section{Pembahasan}

Berdasarkan tabel 1, tidak terdapat hubungan antara Suhu Material dengan Gejala Dermatitis pada pekerja di PT.Elangperdana Tyre Industry dengan nilai p-value 0.246 lebih besar dari nilai $\alpha 0,05$ sehingga Ho diterima. Dari hasil uji statistik odds ratio $(\mathrm{OR})$ sebesar $0.556(95 \% \mathrm{CI}=$ 0.205-1.508) yang artinya responden yang terpapar suhu diatas $40^{\circ} \mathrm{C}$ mempunyai peluang mengalami gejala dermatitis sebesar 0.556 kali lebih besar dibandingkan dengan responden yang terpapar suhu normal (35$40^{\circ} \mathrm{C}$ ). Setiap harinya para pekerja di PT.Elangperdana Tyre Industry yang menjadi responden dari hasil penelitian ini rata-rata kontak dengan material yaitu ban sebanyak kurang lebih 500 ban perhari. Suhu material yang kontak dengan responden pun bervariasi mulai dari $35^{\circ} \mathrm{C}$ hingga $118^{\circ} \mathrm{C}$. Suhu material dinyatakan tidak terdapat hubungan dengan gejala dermatitis disebabkan biasanya karena proses kehilangan panas dengan mekanisme konduksi sangat kecil.

Hal ini pun diperkuat dengan adanya fakta bahwa material berbahan karet bukan pengantar panas yang baik dibanding dengan material berbahan logam. Walaupun bahan baku dari pembuatan ban tersebut menggunakan tali tembaga akan tetapi saat sudah menjadi ban utuh siap pakai, tali tembaga tersebut sudah tertutup rapi atau tertanam di dalam karet ban. Sentuhan dengan benda umumnya memberi dampak kehilangan suhu yang kecil karena dua mekanisme, yaitu kecenderungan tubuh untuk terpapar langsung dengan benda relative jauh lebih kecil dari pada paparan dengan udara, dan sifat isolator benda menyebabkan proses perpindahan panas tidak dapat terjadi secara efektif terus menerus (Diharja,2011). Hal ini sejalan 
dengan keadaan di lapangan yang menunjukkan bahwa para pekerja di area yang kontak dengan panass sudah antisipasi menggunakan 2 buah sarung tangan (di double).

Berdasarkan tabel 2, tidak terdapat hubungan antara Umur dengan Gejala Dermatitis pada pekerja di PT.Elangperdana Tyre Industry dengan nilai p-value 0.678 lebih besar dari nilai $\alpha \quad 0,05$ sehingga $\mathrm{Ho}$ diterima. Variabel umur dapat menyerang semua kelompok umur baik golongan tua maupun muda (Prasetyo, 2014). Sedangkan menurut Cronin (1980) berpendapat bahwa pada dunia industri usia pekerja yang lebih tua menjadi lebih rentan terhadap bahan iritan. Seringkali pada usia lanjut terjadi kegagalan dalam pengobatan dermatitis, sehingga timbul dermatitis kronik. Banyaknya responden yang berumur ( $<31$ tahun) menjadi salah satu alasan variabel umur tidak ada hubungan dengan gejala dermatitis dikarenakan pada umur muda mengalami proses regenerasi kulit lebih cepat dibanding dengan responden umur $\geq 31$ tahun. Penelitian ini sejalan dengan penelitian yang dilakukan Prasetyo (2014) pada pekerja yang terpapar semen di PT. Wijaya Kusuma Contractors bahwa tidak ada hubungan antara umur terhadap gejala dermatitis dengan nilai pvalue 0.874 yang dinilai lebih besar dibanding nilai $\alpha 0,05$.

Berdasarkan tabel 3, tidak terdapat hubungan antara Masa Kerja dengan Gejala Dermatitis pada pekerja di PT.Elangperdana Tyre Industry dengan nilai p-value 0.430 lebih besar dari nilai a 0,05 sehingga Ho diterima. Menurut Suma'mur (1996) semakin lama seseorang dalam bekerja maka semakin banyak dia telah terpapar bahaya yang ditimbulkan oleh lingkungan kerja tersebut. Pekerja yang lebih lama terpajan dan berkontak dengan bahan kimia menyebabkan kerusakan sel kulit bagian luar, semakin lama terpajan maka semakin merusak sel kulit hingga bagian dalam dan memudahkan untuk terjadinya penyakit dermatitis. Masa kerja dalam penelitian ini merupakan jangka waktu pekerja mulai bekerja di pabrik ban PT.Elangperdana Tyre Industry sampai dengan waktu penelitian dilaksanakan. Namun berdasarkan hasil observasi peneliti, responden pada penelitian ini tidak selalu berada di divisi yang sama selama bekerja di PT.EPTI dikarenakan adanya sistem rolling ke divisi lainnya. Hasil penelitian ini tidak sejalan dengan yang dilakukan Mariz (2014) pada karyawan pencuci mobil di kelurahan Sukarame, Bandar Lampung, menunjukkan bahwa ada hubungan antara variabel Masa Kerja terhadap Gejala Dermatitis.

Berdasarkan tabel 4, tidak terdapat hubungan antara Lama Kontak dengan Gejala Dermatitis pada pekerja di PT.Elangperdana Tyre Industry dengan nilai p-value 0.978 lebih besar dari nilai a 0,05 sehingga Ho diterima. Penelitian ini sejalan dengan penelitian yang dilakukan Prasetyo (2014) pada pekerja yang terpapar semen di PT. Wijaya Kusuma Contractors bahwa tidak ada hubungan antara Lama Kontak terhadap Gejala Dermatitis. Namun hasil penelitian ini bertentangan dengan penelitian yang dilakukan Mariz (2014) pada karyawan pencuci mobil di kelurahan Sukarame, Bandar Lampung, bahwa ada hubungan antara Lama Kontak terhadap Kejadian Dermatitis dengan nilai p-value 0.017 (lebih kecil dari nilai 0,05). Berdasarkan hasil observasi di lapangan sebanyak $74.7 \%$ dari total responden dalam sehari kontak dengan material panas kurang dari 5 jam, menjadi salah satu alasan variabel lama kontak tidak terdapat hubungan dikarenakan yang lebih berisiko terkena gejala dermatitis pekerja yang kontak dengan material panas lebih dari 5 jam. 
Berdasarkan tabel 5, tidak terdapat hubungan antara Lama Kontak dengan Gejala Dermatitis pada pekerja di PT.Elangperdana Tyre Industry dengan nilai p-value 0.403 lebih besar dari nilai $\alpha 0,05$ sehingga Ho diterima dan $\mathrm{Ha}$ ditolak. Penelitian ini bertentangan dengan penelitian yang dilakukan oleh Nuraga,et.al (2008) pada karyawan di Perusahaan Industri Otomotif Kawasan Industri Cibitung, penelitian yang dilakukan Mariz (2014) pada karyawan pencuci mobil di kelurahan Sukarame, Bandar Lampung, serta penelitian yang dilakukan oleh Wardani,et.al (2018) terhadap pekerja proyek bandara Juanda menunjukkan bahwa ada hubungan antara penggunaan Alat Pelindung Diri terhadap Kejadian Dermatitis (p-value 0.003). Sebaliknya hasil ini sejalan dengan penelitian yang dilakukan Lestari

\section{Kesimpulan}

Berdasarkan hasil penelitian yang dilaksanakan di PT.Elangperdana Tyre Industry Citereup tahun 2019 tentang faktorfaktor yang berhubungan dengan kontak panas secara langsung terhadapa gejala dermatitis maka peneliti dapat menyimpulkan dari hasil penelitian bahwa tidak terdapat hubungan bermakna antara faktor-faktor yang diteliti seperti suhu material, umur, masa kerja, lama kontak dan penggunaan alat pelindung dengan kejadian gejala dermatitis pada pekerja di curing, mixing, extruding, calendar, serta finishing.
(2007) pada pekerja di PT.Inti Pantja Press Industri dan penelitian Prasetyo (2014) yang menunjukkan bahwa tidak ada hubungan antara penggunaan APD dengan gejala dermatitis pada pekerja.

Tidak adanya hubungan antara penggunaan Alat Pelndung Diri berupa sarung tangan dengan gejala dermatitis pada pekerja di PT.Elangperdana Tyre Industry ini kemungkinan terkait dengan kondisi sarung tangan yang tidak sesuai dengan standar anti panas sehingga seringkali banyak pekerja yang men-double sarung tangan agar tidak terasa terlalu panas.

Kemudian dapat dilihat pula dari 78 responden yang diteliti terdapat 27 responden yang diketahui menggunakan APD tetapi tetap mengalami gejala dermatitis.

Saran bagi peneliti selanjutnya yang akan mengembangkan penelitian dengan judul yang serupa dapat menggunakan metode lainnya untuk mengukur kekuatan atau keakuratan mengenai hubungan antara beberapa variabel penelitian terhadap gejala dermatitis. Saran bagi perusahaan yaitu mempertahankan stok APD atau mengganti dengan sarung tangan anti panas agar lebih efektif dan efisien, serta mempertimbangkan untuk rutin melakukan medical check-up terhadap pekerjanya. 


\section{Daftar Pustaka}

[1] Admin HSE \& $T$ PT.Elang perdana Tyre Industry. 2018. Profil PT.Elang perdana Tyre Industry.

[2] Adzim, Hebbie Ilma. 2013. Pengertian dan Elemen Sistem Manajemen K3 (Keselamatan dan. Kesehatan Kerja). Ahli K3 Umum. Diakses 2 Maret 2019.

[3] Bernard, Thomas E. 2002. Thermal Stress. Dalam: Plog, Barbara A. \& Patricia J. Quinlan, editor. Fundamentals of Industrial Hygiene 5th edition. NSC, USA.

[4] Cronin E. 1980. Contact Dermatitis. Ediburgh, London dan New York: Churchill Livingstone.

[5] Dahlan, S. 2006. Besar Sampel dan Cara Pengambilan Sampel Dalam Penelitian Kedokteran dan Kesehatan. Jakarta: Salemba Medika

[6] Dehghan, Habibollah, Ehsanollah Habibi dan Peymaneh Habibi. 2013. Validation of Questionnaire for Heat strain Evaluation in Women Workers.

[7] Depkes RI. 2008. Dikutip dari http://eprints.ums.ac.id/26066/2/BAB_1 .pdf. Diakses pada 24 Februari 2019

[8] Dinar, Viera Rinida Mauli. 2016. Faktor-faktor yang mempengaruhi kejadian dermatitis kontak akibat kerja pada karyawan salon di kelurahan Pahoman Bandar Lampung. Skripsi:Fakultas Kedokteran. Universitas Lampung. Bandar Lampung.

[9] Diharja, Iffah. 2011. Paparan panas, paparan dingin, dan tekanan turun. Jurnal Hiperkes Universitas Sebelas Maret. Surakarta.

[10] International Labour Organization. 2015. Tren Ketenagakerjaan dan Sosial di Indonesia 2014-2015: Memperkuat Daya Saing dan Produktivitas Melalui
Pekerjaan Layak. Jakarta: International Labour Organization.

[11] Kobyletzki, Laura B. von, et.al. 2012. Evaluation of a Parental Questionnaire to Identify Atopic Dermatitis in Infants and Preschool Children. Journal of allergy volume 2012. Hindawi Publishing Corporation.

[12] Mariz, Donna Rozalia. 2014. Faktorfaktor yang mempengaruhi kejadian dermatitis Kontak akibat kerja pada karyawan pencuci mobil di Kelurahan Sukarame Bandar lampung. Skripsi : Fakultas Kedokteran Universitas Lampung.

[13] Marx, John. 2010. "Chapter 60: Thermal Burns". Rosen's emergency medicine: concepts and clinical practice (edisi ke-7th). Philadelphia: Mosby/Elsevier

[14] Mausulli, Anissa. 2010. Faktor-Faktor yang Berhubungan Dengan Dermatitis Kontak Iritan Pada Pekerja Pengolahan Sampah di TPA Cipayung Kota Depok Tahun 2010. Skripsi Universitas Islam Negeri Jakarta.

[15] National Institute for Occupational Safety and Health. 2016. Criteria for a Recommended Standard: Occupational Exposure to Heat and Hot Environments. Amerika Serikat: National Institute for Occupational Safety and Health.

[16] NIOSH.1986. Criteria For a Recommended Standard Occupational Exposure to Hot Environments. Revised Criteria: U.S Department of Health and Human Services National Institute for Occupational Safety and Health.

[17] Notoatmodjo, S., 2012. Metodologi PenelitianKesehatan. Jakarta: Rineka Cipta. 
[18] Nuraga, Wisnu. 2008. Dermatitis kontak pada pekerja yang terpajan dengan Bahan kimia di perusahaan industri otomotif kawasan Industri Cibitung Jawa Barat. Jurnal Kesehatan Fakultas Kesehatan Masyarakat. Universitas Indonesia.

[19] Occupational Safety and Health Administrtion. 1999. Technical Manual Section III Chapter 4 - Heat stress

[20] Occupational Safety and Health Service (OSHS). 1997. Guidelines For The Management of Work In Extreme of Temperature. Occupational Safety and Health Service Department of Labour. Wellington.

[21] Pramesthi, Kartika Wahyu. 2017. Analisis Thermal pada atap beton dan atap hijau (Green Roof) di kampus Dramaga Institut Pertanian Bogor. Jurnal skripsi: Fakultas Teknologi Pertanian, Institut Pertanian Bogor. Bogor.

[22] Prasetyo, Dwi Ambang. 2014. Faktorfaktor yang berhubungan dengan dermatitis kontak iritan pada tangan pekerja konstruksi yang terpapar semen di PT.Wijaya Kusuma Contractors. Skripsi: Fakultas Kedokteran dan Ilmu Kesehatan. Universitas Islam Negeri Syarif Hidayatullah Jakarta.

[23] Prastyawati, Fariya Eka. 2018. Tekanan Panas, Faktor Pekerja Dan Beban Kerja Dengan Kejadian Heat Strain Pada Pekerja Pembuat Kerupuk (Studi Di Industri Kerupuk Kelurahan Giri Kabupaten Banyuwangi).Skripsi: Fakultas Kesehatan Masyarakat. Universitas Jember.

[24] Puspita, Agil Helien. 2012. Analisis Tekanan Panas Dan Tingkat Keluhan Subjektif Pada Pekerja Di Area Produksi Pelumas Jakarta Pt
Pertamina (Persero) Tahun 2012. Skripsi: Fakultas Kesehatan Masyarakat Universitas Indonesia.

[25] Sularsito, SriAdi. Djuanda, Suria. Dermatitis dalam Ilmu Penyakit Kulit dan Kelamin edisi keenam. Jakarta : Badan penerbit fakultas kedokteran universitas indonesia. 2010

[26] Suma'mur. 1996. Perusahaan dan Kesehatan Kerja. Jakarta : PT. Toko Gunung Agung

[27] Suma'mur. 2009. Higiene Perusahaan dan Kesehatan Kerja. Jakarta: Sagung Seto.

[28] Suryani, Febria. 2011. Faktor-faktor yang berhubungan dengan dermatitis kontak pada pekerja bagian processing dan filling PT.Cosmar Indonesia Tangerang Selatan tahun 2011. Skripsi: Fakultas Kedokteran dan Ilmu Kesehatan. Universitas islam Negeri Syarif Hidayatullah Jakarta.

[29] Wardani, Harumi Kusuma. 2018. Faktor Yang Berhubungan Dengan Dermatitis Kontak Akibat Kerja Pada Pekerja Proyek Bandara. Jurnal: Fakultas Kedokteran Universitas Pembangunan Nasional "Veteran" Jakarta.

[30] WHO. 2000. Obesity: preventing and managing the global epidemic. WHO Technical Report Series 894. Geneva : World Health Organization.

[31] Witasari, D. \& Sukanto, H., 2014. Dermatitis Kontak Akibat Kerja: Penelitian Retrospektif. Berkala Ilmu Kesehatan Kulit dan Kelamin Periodical of Dermatology and Venereology 162, pp.161-67

[32] Wolff, K. \& Johnson, R.A., 2008. Fitzpatrick's Color Atlas and Synopsis of Clinical Dermatology Sixth Edition. New York: Mc Graw Hill- Medica 